\title{
Service Interaction Platform Technologies Providing High Value-added ICT Services
}

\author{
Takashi Kai, Atsushi Hirao, Daisuke Miyamoto, Yuko Ueda \\ Hitachi Co., Ltd., Public Systems Division, \\ 1-6-27 Shin-suna, Koutou-ward, Tokyo 136-8632, Japan
}

\begin{abstract}
In ubiquitous network society, various kinds of entities offer online services. For the user's convenience, providing high value-added service such as one-stop online service is in urgent need. One-stop services transform citizens' daily lives more convenient by, for example, improving online application procedures to local governments and companies. Service interaction platform technology, which securely and flexibly combines various kinds of services operated under different sites or established under different system architectures, is essential to realize high value-added services. In this paper we propose the core components of service interaction platform technology, and its effectiveness measured through demonstration experiments. The scenario of moving is applied in the experiments.
\end{abstract}

\section{Introduction}

The number of Internet user in Japan is increasing rapidly as the explosive spread of broadband and mobile network terminals. Today the Internet is becoming a fundamental social infrastructure, and the state of service offered by the Internet has changed. People use the Internet not only for collecting and exchanging information, but also for applications and transactions. Citizens hope a number of services can be provided through the Internet, including application procedures to central and local governments.

From e-Japan Strategy II [1], Japanese government has shifted the policies to increase users' convenience, and the Ministry of Internal Affairs and Communications 
promotes u-Japan Policy [2] along with the strategy. The target of U-Japan Policy is the realization of the ubiquitous network society by 2010 , which anyone can always connect to network for anything and at anywhere. Toward the target, various measures have carried out for the realization of "one-stop electronic administration for citizens".

Regarding application procedures to governments, it is expected that the broad range of administrative procedure will be offered online together with service of private sector. It will enormously increase citizens' convenience and efficiency of local governments, if citizen can file applications for all kinds of public and private services online, without going out to windows or writing down same information several times in different application forms.

We define such one-stop online service as high value-added service, as citizens can apply for governments and companies at one time from anywhere, which had been impossible for a long time. One-stop service means that certain service is conducted and completed by single application of service. Here, service includes collecting information and processing applications.

In this paper, we propose service interaction platform technology, which is necessary to realize high value-added services. The remainder of this paper is organized as follows: Section 2 shows the example of the benefit of high value-added service. Section 3 shows the existent problems and the outline of core component of service interaction platform technology. Section 4 shows the effectiveness of the technology measured by demonstration experiments. Section 5 shows conclusion and future activity to disperse the technology.

\section{Aims of the Research: Providing High Value-Added Services}

Service interaction platform technology is necessary for offering high value-added services to user. In this chapter we exemplify the benefit of high value-added services with one-stop online moving case, and explain the specific scenario applied in the demonstration experiments.

\subsection{The Benefit of High Value-Added Services: the Case of One- Stop Online Moving Service}

High value-added service such as one-stop online service increases convenience of citizens and efficiency of office work of local governments. Citizen can conduct application procedures to governments and companies by single application via online. At the same time, the employee of local governments can refer and confirm information of other regional governments through the online inquiry. As an example of the benefits brought by one-stop online service, we explain the present image and the future image of application procedures at the time of moving.

In the case of moving, there are plenty of applications to be done. For instance, citizen has to turn in application form of change-of-address registration to civic affairs division and welfare division, and application form of allowance for children to child support division in the local government the citizen moves in (Fig. 2.1). 
Change-of-residence registration is also required to banks and other companies. In addition, cancellation and new application of electricity, gas, water service, etc., must be done to utility companies. In present, citizen has to go to window of local government and companies, and submit separate application form at each window, writing down same information many times. Employee of local government that citizen moves in (local government A) has to inquire of local government the citizen moves out (local government B) by phone, if the application submitted by the citizen requires reference or confirmation of the information local government $\mathrm{B}$ has.

In such a case, one-stop online service increases citizens' convenience by great deal. For instance, citizen can access to regional portal site and apply applications to local government A, utility companies and banks electronically from home. It reduces the time to visit each window and write down same information repeatedly. Citizen can also confirm the progress of process from portal site.

One-stop online service also increases the efficiency of office work of local governments and companies. Local governments, utility companies and banks can receive the applications and return the results electronically. Moreover, Local government A can refer and confirm the information of local government B through the network. Conventionally citizen has to get a proof of earnings of previous year from government B and turn it in to government A to get allowance for child, and the employee of local government A has to manually input the data to child allowance system. As there are plenty of necessary attached documents, this is one of the reasons that processing application takes time. However, in one-stop online service, local government A can refer and confirm information of earnings on screen of child allowance system by service interaction of both local governments.

\subsection{Scenario Applied in the Demonstration Experiments}

In demonstration experiments, the scenario of one-stop online moving service is applied. We assume that a family moves from local government B to local government A. The family applies changing address to civic affairs division and welfare division of local government $\mathrm{A}$, bank and electric power company, and applies allowance for children to child support division of local government $\mathrm{A}$.

The specific flow of process and information is described in Fig. 2.1. The family accesses to regional portal site, fills necessary information in application forms and turns them in electronically. Regional portal site receives the submitted applications and the business process management (BPM) function controls the process of onestop service between local government A and B, bank and electric power company. Through the Internet the BPM function distributes the applications to local government A, bank, electric power company respectively. To bank the application is distributed after local government A finishes the procedures, since bank needs the address information local government A confirms. 

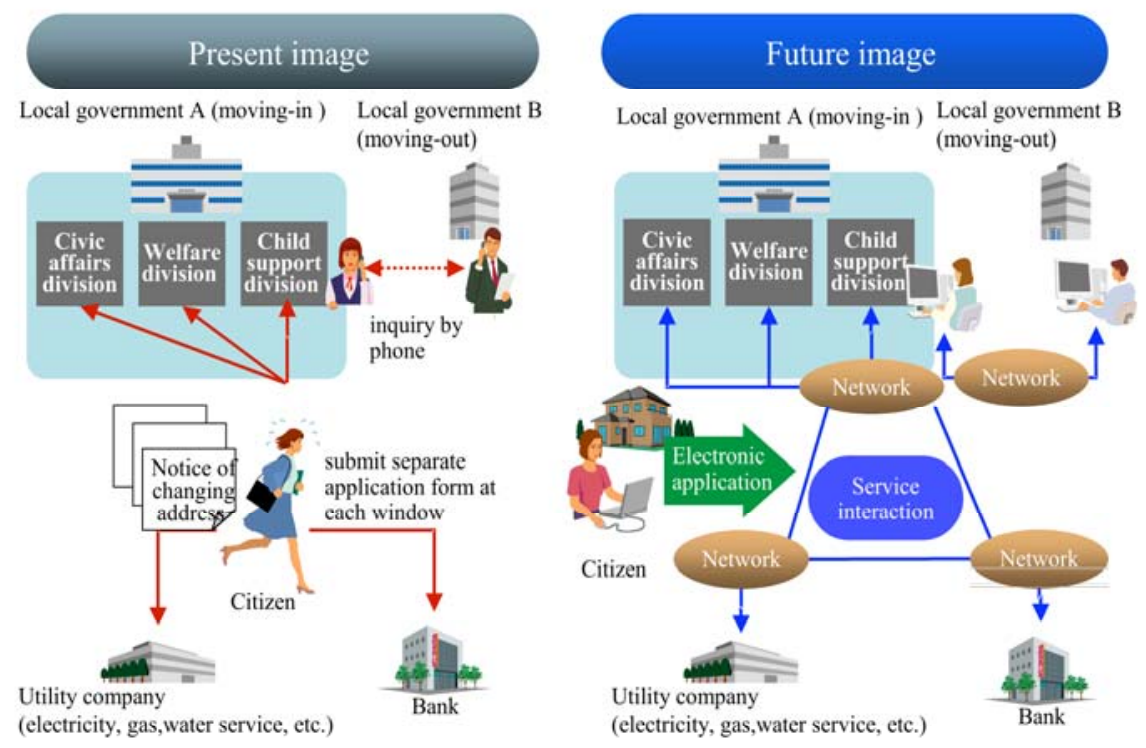

Fig. 1.1. Present and future image of moving service

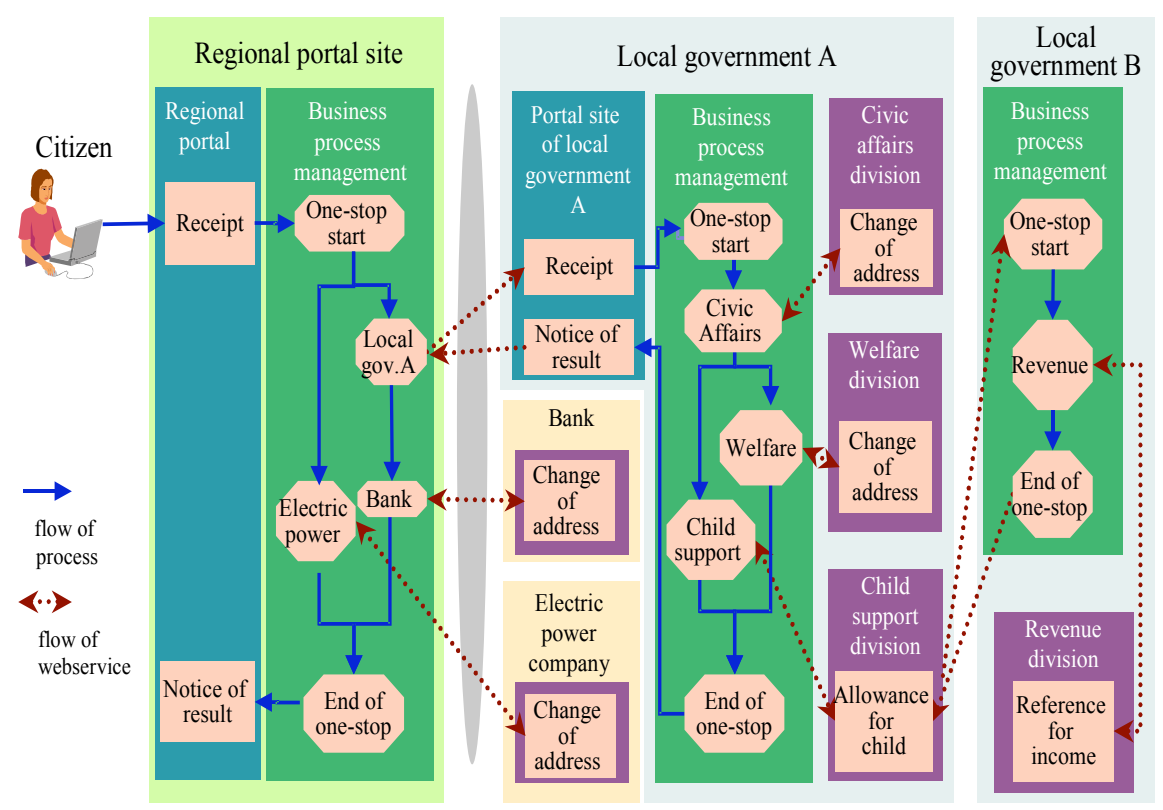

Fig. 2.1. Flow of process and web service in one-stop online moving service

In local government $\mathrm{A}$, bank and electric power company, procedures are processed internally. In local government $A$, portal site receives the application data, and BPM function controls the process of one-stop service between civic affairs, welfare 
and child support division. After civic affairs division registers the address of the family, welfare division registers the address and child support division processes the application of allowance for child. In order to judge whether the allowance is applicable, child support division of local government A asks revenue division of local government B to refer the previous year's income of the family. With the information acquired from local government B, child support division processes proper procedures. When one-stop service within local government A is finished, it returns the notice of result to BPM function of regional portal site.

Application of changing address to bank and electric power company is also processed the same way. When one-stop service between local government A and B, bank and electric power company has finished, regional portal site returns the result to the family, and the family can confirm the result from the screen of regional portal site. Regional portal site shows the progress information of applications, when the family asks for the result in the middle of one-stop service.

\section{Outline of Service Interaction Platform Technology}

There are technical problems peculiar to online one-stop service between multiple sites. We have divided the problems from the aspects of service development, service supply and service administration, and have developed core component technologies that provide solution to each of those problems. They are design pattern technology, authentication interaction platform technology and integrated monitoring technology [3]. In this section we describe the existent problems concerning online one-stop service, and the outline of core components of service interaction platform technology.

\subsection{Design Pattern Technology}

In order to design web service between multiple sites, the developer needs to grasp the specifications of each site and consider the best way of these combinations. It takes man-hour, and it is also difficult to make use of know-how of past projects. Design pattern technology is developed to increase the efficiency of designing interactive web service.

Design pattern is a model form of designing system, which includes business process of one-stop service and interaction of systems. Design pattern technology is the technology that streamlines design, defines and verifies operation of the interactive service over multiple sites, and is applicable to the phase of designing interactive service, generating definition and verifying operation.

In design phase of interactive web service, functional requirements and nonfunctional requirements such as performance, reliability and security, should be defined. Conventionally system engineer manually understands the requirements, creates a suitable model and defines the web service. There are tools that streamline these processes, however, only functional requirements are described with these existent tools. Engineer has to define non-functional requirements by their own, usually based on know-how from past projects. In order to describe non-functional requirements, design pattern technology regulates design pattern language, the describing method of non-functional requirements. By utilizing design pattern language, non-functional re- 
quirements are described as expanded description of XML, and design pattern can have non-functional information together with functional information.

In definition creation phase, the technology provides designing tool, with which engineer can automatically generate BPEL (Business Process Execution Language) that defines business process of interactive service, and WSDL (Web Service Description Language) that defines interface of services, by selecting appropriate design patterns from pattern pool and specifying certain conditions. Process of definition creation becomes efficient, by storing the design patterns that have been developed in past projects and reuse them to new projects. The technology also provides the tool, which converts BPEL and WSDL from and to UML (Unified Modeling Language), the general description of designing document. As the definition written by UML is convertible to BPEL and WSDL, previously generated definitions in other projects are applicable to the web service, and the contrary is also realized.

In operation verification phase, the technology automatically generates service simulator, which is necessary for verifying the operation of the generated web service.

With this technology, engineer with scarce experience can understand and design interactive web service between multiple sites easily, and the developed design patterns and definitions are reusable to future projects. Design of web service becomes efficient, and thus the efficiency of design enormously improves (Fig. 3.1).

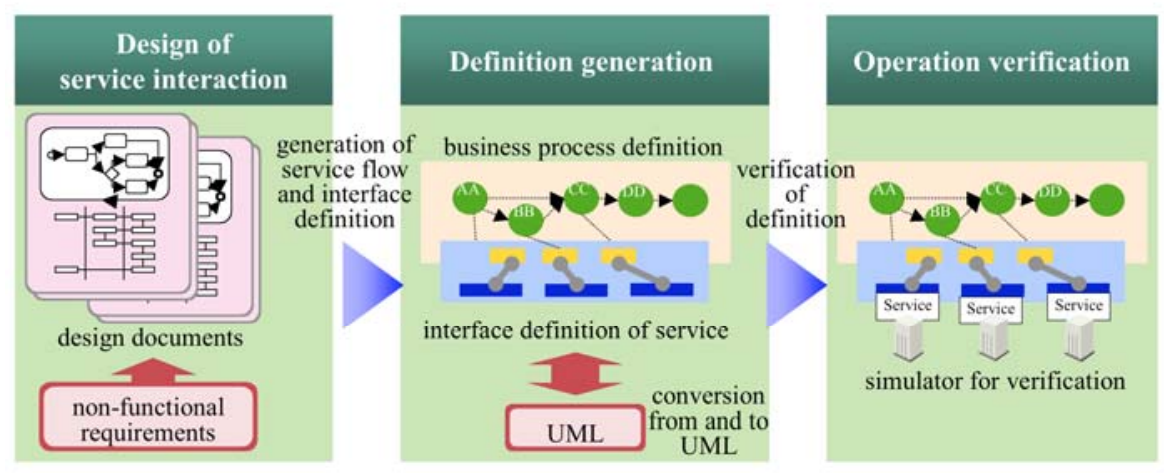

Fig. 3.1. Outline of design pattern technology

\subsection{Authentication Interaction Technology}

For the users' convenience, it is aspired that user can get one-stop online service by single sign-on, which enables to gain access to the multiple services by getting authentication only one time. However, the risk of drain of privacy information becomes higher in one-stop service, because if user's identification data (ID) of single site is leaked, identification of multiple sites becomes possible, and the information registered at various sites can be gathered and abused. Authentication interaction technology is developed in order to prevent the drain of personal information in onestop interactive service. 
Authentication interaction is achieved by setting up authentication center, which manages every user's log-in ID and temporary IDs and sends temporary ID by request of each site. Log-in ID is the unique identification user uses to access the account of regional portal site and get interactive web services. Temporary ID is the unique identification of user used in the communication between authentication center, regional portal site and service providers. Temporary ID is transformed to real ID within each site. Real ID is the unique identification of user used in each site.

Specific mechanism of authentication interaction is shown in Fig. 3.2. When user A wants to get services provided by site $\mathrm{A}$ and $\mathrm{B}$, the user accesses to regional portal site and put in log-in ID (123) and password for the regional portal site (\#1). At authentication center, authentication interaction function connects the log-in ID (123) to user A's temporary ID of regional portal site (zzz) (\#2). The temporary ID (zzz) is sent to regional portal site, authentication interaction function of regional portal site receives the ID, and the temporary ID (zzz) is connected to real ID of user A (ZZZ) inside the regional portal site (\#3). Regional portal site calls service of site A with user A's temporary ID of regional portal (zzz). At site A authentication interaction function receives the ID (zzz) and asks authentication center for the temporary ID of site A whose temporary ID of regional portal is zzz (\#4). The temporary ID of site A (aaa) is sent to site A, and authentication interaction function of site A connects the temporary ID (aaa) to real ID of user A (AAA) inside site A (\#5). The same mechanism of temporary ID (bbb) and real ID (BBB) works for site B (\#6 and \#7). When the services of site $A$ and $B$ are terminated, regional portal site returns the result of one-stop service to User A.

The characteristic of the technology is that real IDs of certain user differ at each site and are managed only within the site, and authentication center does not know any of real IDs. Therefore, even though the communication between authentication center and sites is tapped, it doesn't connect to the leak of identifiable information of user. By applying the technology, disclosure of personal information is minimized, and user can utilize safe interactive one-stop service by logging in to regional portal site only once. 


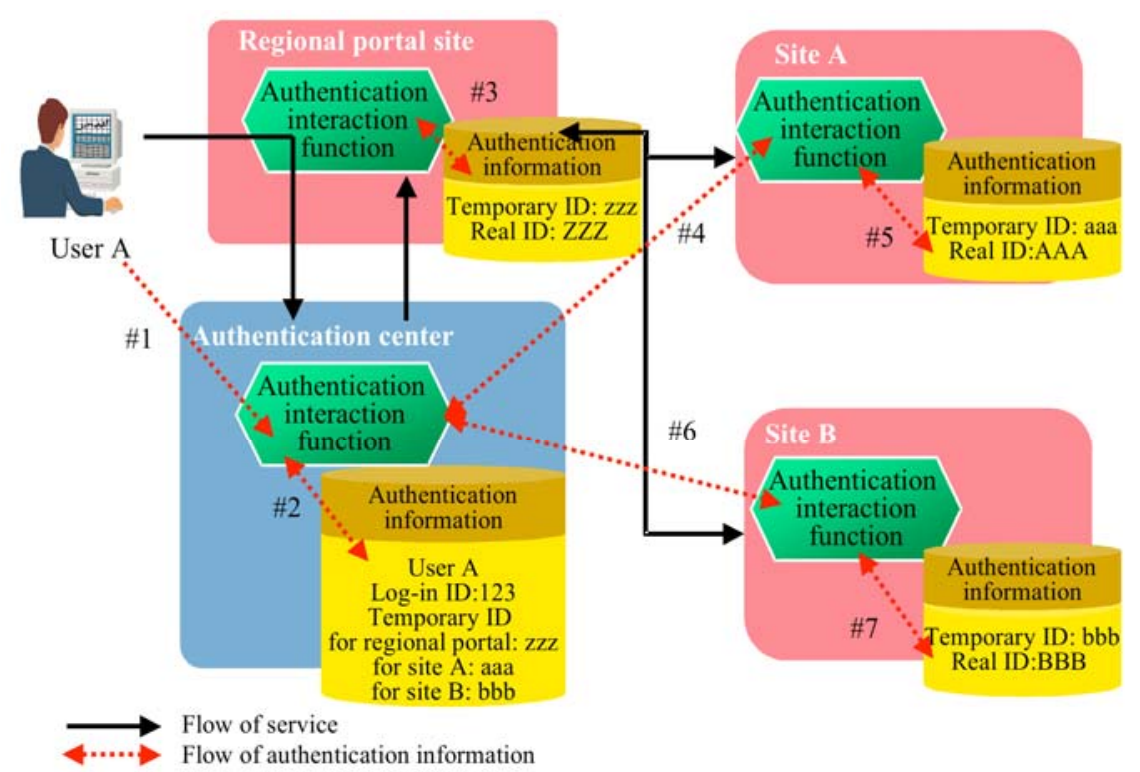

Fig. 3.2. Image of authentication interaction technology

\subsection{Integrated Monitoring Technology}

In one-stop online service between multiple sites, the data exchanged between sites increases. The increase of data affects performance of whole interactive services, and the management cost of interactive service becomes higher. Easy understanding of system operation situation and early detection of system resource failure are necessary for providing stable online one-stop service. Integrated monitoring technology is the technology that collects system resource data from different sites, integrates and analyzes them and provides appropriate system configuration plan. System resource is the resource of CPU or network ports, used at the time of execution of business process and services.

The technology regulates interface, provides tools and monitors. Firstly, the technology regulates the integrated monitored data and managed information interface, which are based on web service specification. As conventional technologies adopt various forms of system resource data, the unified form of data and its interface is necessary. Secondly, the technology develops the tool that generates and set in the module, which converts system resource data in various formats to integrated monitored data. The technology also provides monitor that visualize the resource utilization efficiency of multiple systems in different sites. Moreover, the technology develops integrated managed information analysis tool, which analyzes the collected integrated monitored data and generates system configuration plan, for more efficient use of system resource. The tool features considering cycle of operation load together with peak of operation load, which the existent similar technologies have not achieved. As it considers the peak information of certain interval of time, more reliable system configuration plan is calculated. 
Concretely, monitoring information service function collects resource data from server in site A, B and C respectively. The data are converted to integrated monitored data, sent to surveillance center via the Internet. The data are integrated, visualized and analyzed, so that service administrator at surveillance center can easily understand the utilization rate of system resource in multiple sites, and draw better system configuration plan (Fig. 3.3). Therefore the efficient and stable offering of interactive service is realized.

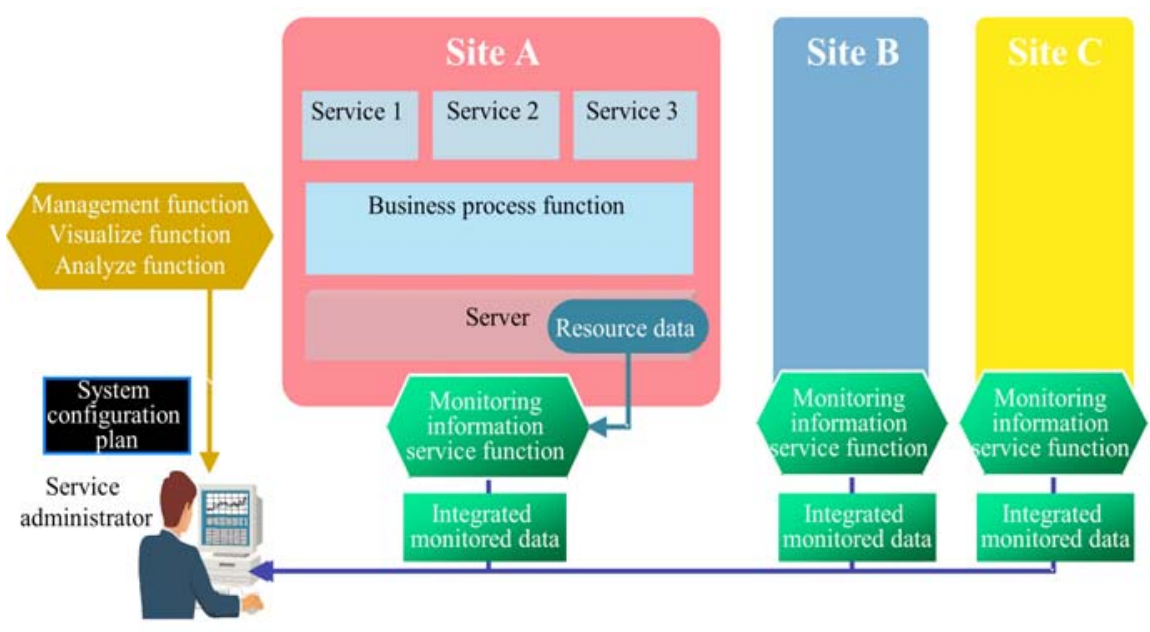

Fig. 3.3. Image of integrated monitoring technology

\section{Effectiveness of Service Interaction Platform Technology}

In this section we describe effectiveness of the core component technologies of service interaction platform technology. The effectiveness is measured through the demonstration experiments. One-stop online moving service scenario explained in the section 2 is applied to the experiments.

\subsection{Effectiveness of Design Pattern Technology}

Designing process includes modeling processing flow, generating BPEL definition and verifying BPEL operation. In modeling processing flow, engineer usually depicts flow based on BPMN (Business Process Modeling Notation), standardized description of business process. The image of BPMN depicted by the designing tool, which the design pattern technology develops, is shown in Fig. 4.1. Engineer firstly chooses appropriate design pattern from design pattern pool, and depicts processing flow. When engineer confirms the flow and orders to generate BPEL, BPEL with information of non-functional requirements is generated automatically. 


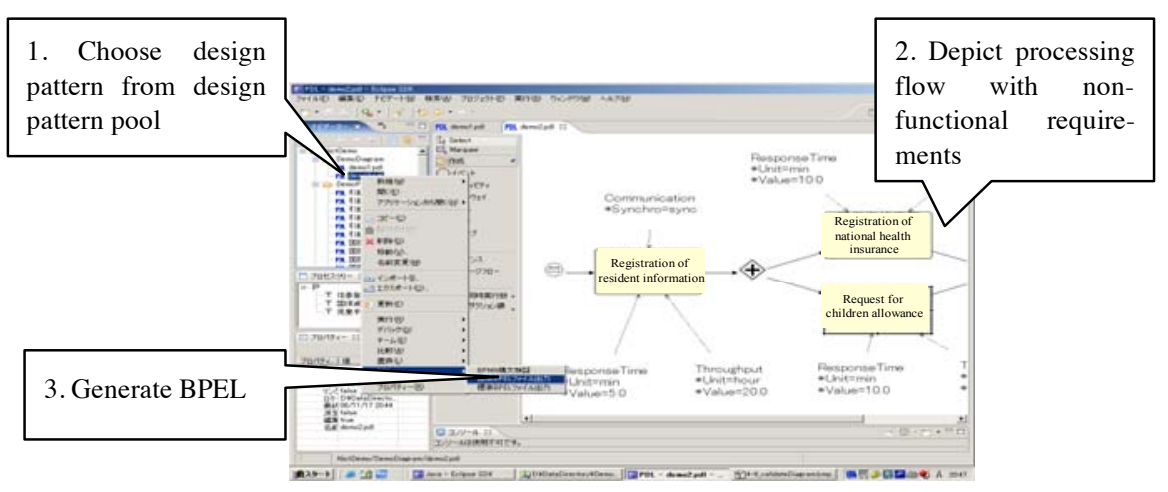

Fig. 4.1. Image of generating BPEL by utilizing the developed tool

The effectiveness of design pattern technology is measured from the viewpoint of design and reuse of design. In each case, the time required by manual work is compared to the man-hour required by utilizing the designing tool developed by the technology. In design of service interaction, the man-hour needed for modeling and describing the processing flow in BPEL is measured. The required man-hour by manual work is one week. It shortens to 30 minutes, when the designing tool is applied. In reuse of design, the man-hour needed for creating UML descriptions from processing flow written in BPEL, is measured. The required man-hour is reduced from 3 hours to 2 minutes, when the designing tool is applied (Table 4.1).

Designing web service is indispensable procedure for offering one-stop moving service. The total time and cost of designing interactive services, such as collaborative one-stop service between local governments and companies, will be extremely smaller by applying the developed technology. Engineer can use the reduced time to deeper understanding of generated designs and planning better services, etc. In addition, as engineer can automatically convert UML descriptions to BPEL definitions and vice versa, the design know-how accumulated in other projects can be easily utilized for own project. It contributes to better productivity of designing work.

In the demonstration experiment, man-hour for detailed design work is not taken into consideration. In actual development, the additional man-hour is expected to be required, as detailed design work becomes necessary. For instance, at the time of calling service, the definition creation work for data conversion becomes necessary. Manhour based on actual development should be examined by each project. 
Table 4.1. Man-hour requirement comparisons of conventional method and design pattern technology

\begin{tabular}{|c|l|l|l|l|l|}
\hline \multirow{2}{*}{ No. } & \multirow{2}{*}{ Process } & \multicolumn{4}{|c|}{ Result of experiment } \\
\cline { 3 - 6 } & & Conventional method & \multicolumn{2}{|l|}{ Design pattern technology } \\
\cline { 3 - 6 } & $\begin{array}{l}\text { Method } \\
\text { Design of } \\
\text { service in- } \\
\text { teraction }\end{array}$ & $\begin{array}{l}\text { Describe proc- } \\
\text { essing flow } \\
\text { by manual work }\end{array}$ & 1 week & $\begin{array}{l}\text { Choose appropriate } \\
\text { design pattern from } \\
\text { design pattern pool }\end{array}$ & 30 minutes \\
\hline 2 & $\begin{array}{l}\text { Creation } \\
\text { of UML }\end{array}$ & $\begin{array}{l}\text { Create UML } \\
\text { descriptions } \\
\text { by manual work }\end{array}$ & 3 hours & $\begin{array}{l}\text { Generate UML } \\
\text { descriptions auto- } \\
\text { matically }\end{array}$ & 2 minutes \\
\hline
\end{tabular}

\subsection{Effectiveness of Authentication Interaction Technology}

The possibility of authentication interaction is measured based on the user ID information shown in Table 4.2. Regional portal site, local government and electric power company have real ID and temporary ID, respectively. Authentication center manages log-in ID and three temporary IDs. There is also bank, but other way of authentication is conducted at bank. Application pattern is five patterns, which are several combinations of operations executed in local government, electric power company and bank, based on online one-stop moving service scenario. Rejection of application is included in some application patterns. It is proved that in each application pattern authentication is executed correctly and operation is concluded properly. Therefore, user can utilize one-stop service by single sign-on to regional portal site, at the same time preventing leak of personal information.

Table 4.2. ID information applied in demonstration experiment

\begin{tabular}{|l|l|l|}
\hline \multicolumn{1}{|c|}{ Site name } & \multicolumn{1}{c|}{$\begin{array}{c}\text { Log-in ID/ } \\
\text { Real user ID }\end{array}$} & \multicolumn{1}{c|}{ Temporary user ID } \\
\hline \multirow{3}{*}{ Authentication center } & \multirow{2}{*}{ idp_user1 } & chiiki_user1_sp (for regional portal site) \\
\cline { 3 - 3 } & & portal_user1_sp (for local government) \\
\cline { 3 - 3 } & & denryoku_user1_sp (for electric power company) \\
\hline Regional portal site & chiiki_user1 & chiiki_user1_sp \\
\hline Local government & portal_user1 & portal_user1_sp \\
\hline Electric power company & denryoku_user1 & denryoku_user1sp \\
\hline
\end{tabular}




\subsection{Effectiveness of Integrated Monitoring Technology}

The effect of integrated monitoring technology is measured from the viewpoint of calculation of appropriate system configuration plan. Integrated management information analysis tool analyzes the collected integrated monitored data and calculates the appropriate system configuration plan for local government $\mathrm{A}$.

The environment of demonstration experiment is shown in Fig. 4.2. There is monitoring information service function, which collects system resource data from operational servers in local government A, converts them to integrated monitored data and send to surveillance client terminal via the virtual private network. Surveillance client terminal supervises and analyzes integrated monitored data of local government A.

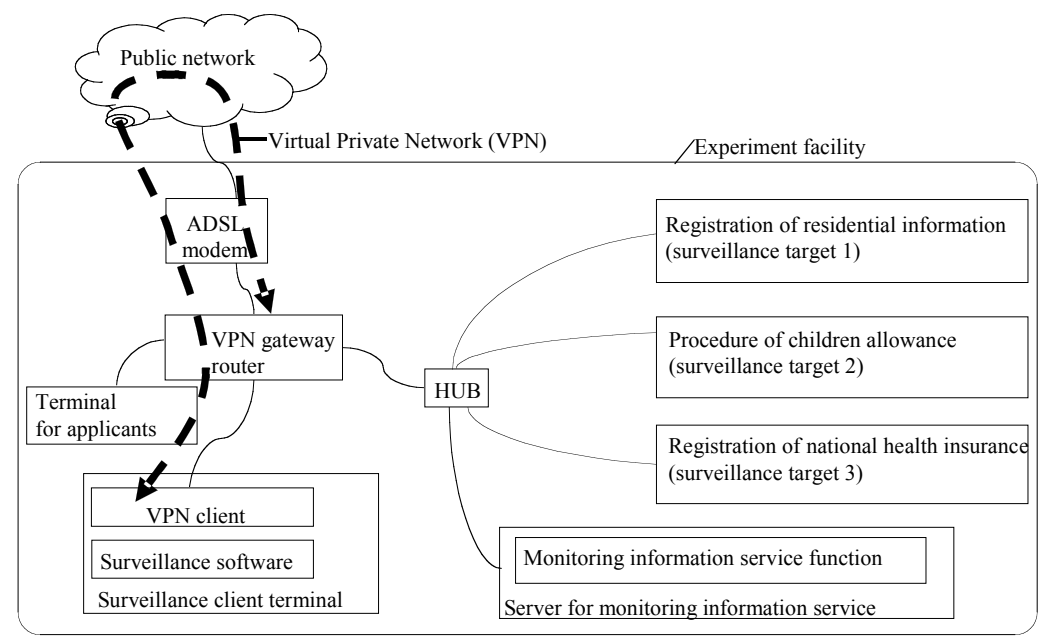

Fig. 4.2. Demonstration experiment environment regarding integrated monitoring technology

Condition in the experiment is as follows. The operations executed in local government A are registration of residential information, procedure of children allowance and registration of national health insurance. One physical server is used for each operation. Application pattern is eight patterns, which is the combination of three operations. Applications are filed in certain interval, and the number of applications filed on Wednesday is six times more compared to other days of the week. The number of applications examined changes in every 30 minutes. Ten applications are examined in first 30 minutes, fifteen applications in second 30 minutes, twenty applications in third 30 minutes, and twenty-five applications in last 30 minutes.

Utilization efficiency is calculated by the following formula.

Utilization efficiency $=($ total sum of average amount of resource used $/$ total sum of resource) $* 100$ 


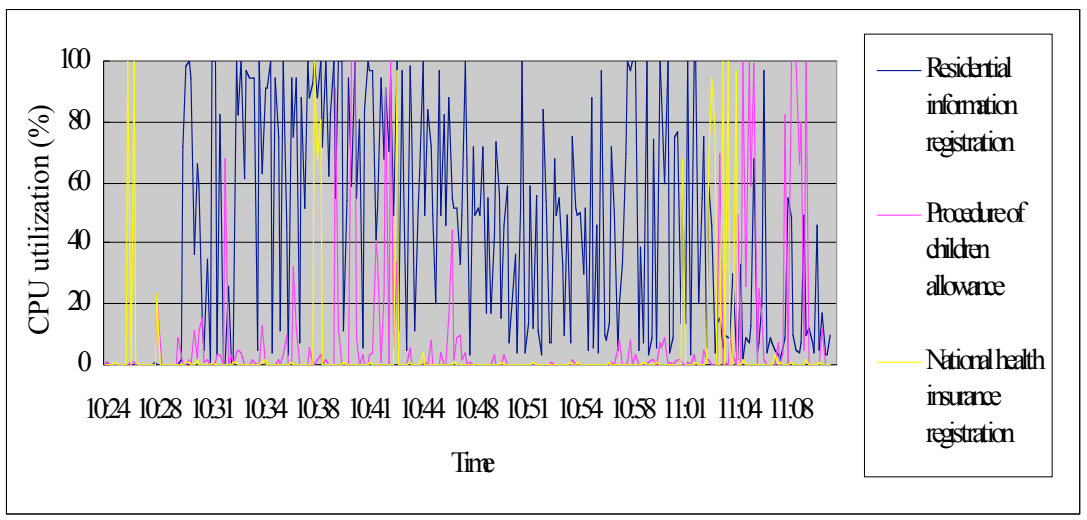

Fig. 4.3. CPU Utilization on Wednesday

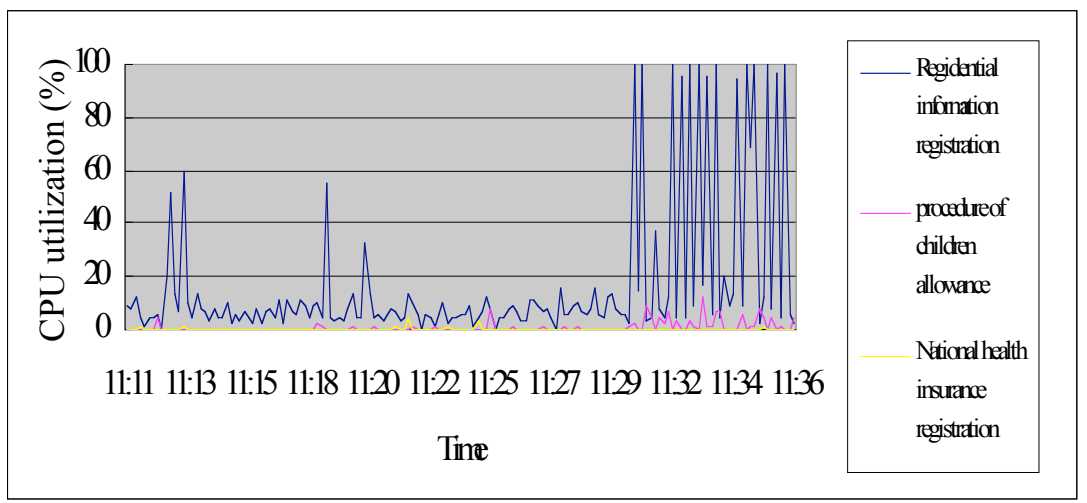

Fig. 4.4. CPU utilization on the other days of the week

Fig. 4.3 and Fig. 4.4 show CPU Utilization of three physical servers in certain time interval on Wednesday and on the other days of the week. The cumulative CPU utilization of three servers on Wednesday is more than $200 \%$. Therefore, three sets of server are necessary. On the other hand, on the other days of the week, the cumulative CPU utilization is less than $100 \%$ and single server can conduct the three operations. After the system concentration, average utilization efficiency of CPU increases from $8.0 \%$ to $8.8 \%$. In other words, utilization efficiency ratio improves approximately $10 \%$.

By utilizing the technology, service administrator at surveillance center can grasp the utilization efficiency of system resource in single site and plan more efficient system configuration. The technology is also applicable in the situation that the systems are dispersed in multiple sites. Thus service administrator can easily understand the condition of system resource and provide stable one-stop service. 


\section{Conclusion}

The effectiveness of design pattern technology, authentication interaction technology and integrated monitoring technology is verified by the demonstration experiments applying one-stop online moving service scenario. These technologies are indispensable for service interaction between multiple sites. We will propose the technologies to Association for Promotion of Public Local Information and Communication (APPLIC), which promotes the standardization activities of Local Government ICT Platform. Local Government ICT Platform is the standard specification documents for interacting and combining various services on network and building new services, based on the concept of Service Oriented Architecture (SOA). We will contribute to the realization of high value-added service through proposal activity of the technologies and commitment to APPLIC.

\section{Acknowledgments}

The technologies are developed as a result of contract research 'research and development regarding service interaction platform technologies that enables providing high value-added service by interacting services operated under different policies or different architectures' sponsored by National Institute of Information and Communication Technology (NICT) in 2005-2007 fiscal year.

\section{References}

1. IT strategic Headquarters, e-Japan Strategy II , 2003.

2. Ministry of Internal Affairs and Communications, u-Japan Policy, 2004.

3. National Institute of Information and Communication Technology, Contract research accomplishment report of research and development in 2007 fiscal year regarding service interaction platform technologies that enables providing high value-added service by interacting services operated under different policies or different architectures, 2008. 